\title{
An intriguing association between dental and mental pathology in addicted and control subjects: a cross-sectional survey
}

IN BRIEF

- This paper demonstrates a statistical association between dental and mental illness in normal clinical patients.

- This finding shows that this relationship is strengthened in patients addicted to illicit drugs who form a high risk group for both dental and mental disease.

- This suggests that such disorders may share common aetiopathological pathways such as common risk factors between the two sets of pathologies.

\section{A. S. Reece'}

Background Recent clinical studies suggest that substance use may be associated with an acceleration of the ageing process, possibly related to a deficit of stem cell number or function. As this clinic had access to both medical and drug dependent patients, we tested the hypothesis that there may be an association between previously identified deficits.

Methods A cross-sectional survey was performed looking at both dental and mental dysfunction. Both a dental index (DI) and a mental index (MI) were defined as previously described and utilised as summary measures of such pathology. Findings From 249 substance use disorder (SUD) and 134 general medical controls (N-SUD), 248 and 91 patients were selected with ages less than 57 years as the primary focus of analysis. The mean ( \pm S.D.) ages (32.59 \pm 7.98 vs $35.65 \pm 15.45$ years) were similar. The DI was found to correlate with the $M I$ in a significant manner in SUD ( $R=0.14, p=0.03), N-S U D$ ( $R$ $=0.27, p=0.009)$ and in the whole group $(R=0.17, p=0.001)$. The (univariate) association of $\mathrm{MI}$ with $\mathrm{DI}(\mathrm{p}=0.019)$ and DI with MI ( $p=0.0037)$ remained highly significant at multivariate regression after adjustment for psychiatric diagnoses and measures of dose-duration exposure to common addictive drugs. The qualitative appearance of the surfaces of best fit for the relationship between age, DI and MI was different in the two groups. Conclusions These results suggest that the robust statistical association between dental and mental pathology may be related to common underlying pathophysiological mechanisms such as a progeroid or stem cell deficiency process in clinical addiction.

\section{INTRODUCTION}

The link between dental infections and systemic disease has received increasing attention in recent years. This relates particularly to carotid and coronary atherosclerotic disease, ${ }^{1-6}$ and both infective ${ }^{7-10}$ and immunological ${ }^{11-13}$ mechanisms have been suggested. Less attention would appear to have been paid to possible mechanistic links between neuropsychiatric and dental illness. ${ }^{14,15}$

Addiction has long been an important source of health impairment globally. Indeed in 2007, the United Nations Office of Drugs and Crime (UN ODC) estimated that the annual global

\footnotetext{
'Medical School, University of Queensland/Southcity Family Medical Centre, 39 Gladstone Rd, Highgate Hill, Brisbane, Queensland, Australia, 4101

Correspondence to: Dr A. Stuart Reece Email: sreece@bigpond.net.au
}

Online article number E22

Refereed Paper - accepted 27 July 2008

DOI: $10.1038 /$ sj.bdj.2008.932

${ }^{\circ}$ British Dental Journal 2008; 205: E22 prevalence of illicit drug use was 200 million people $(4.8 \%$ of the global population), the monthly prevalence was 110 million (2.6\%), and that problem drug use was experienced by 25 million people $(0.6 \%) .{ }^{16}$ Annual prevalence rates of cannabis use were 158 million and for opiates 15.6 million people. Despite increasing interdiction efforts, ${ }^{16}$ addiction, particularly to intravenous drugs, carries important associations with the spread of blood-borne viral (BBV) diseases including HIV and hepatitis B and $\mathrm{C},{ }^{17}$ and is an important focal point both for criminal and terrorist activity. ${ }^{16}$ While certain disorders are well recognised to occur at higher rates in patients with substance use dependence (SUD), such as BBV and tuberculosis, a full statement of the illnesses occurring with increased frequency in this group is distinctly compendious ${ }^{18}$ and reads not unlike a list of the disorders of old age. ${ }^{19}$ The greatly elevated mortality rate associated with the disorders of substance dependence is also well known and well documented. ${ }^{20-25}$

In the process of examining the agedependent prevalence of psychopathology including psychoses in our own drug-dependent patients, we noted that the age-dependent profile of such disorders was very different in a group of addicted patients compared to medical controls, with the drug-dependent group developing more psychopathologies more rapidly and with greater severity than the medical controls. ${ }^{26}$ Drug-dependent patients develop a wide variety of disorders in addition to the infective and neuropsychiatric diseases for which they are well known, and these appear similar to the disorders of old age. ${ }^{19}$ Moreover, this multisystem dysfunction, which includes severe coronary artery disease, pulmonary fibrosis and nephrosclerosis, has been shown to follow a greatly accelerated time course. ${ }^{27}$ Addiction is of course well known to be associated with greatly elevated 
mortality, variously estimated at 10-70 times that of control populations. ${ }^{20,22,25,28}$

The stereotypical unkempt appearance of many street SUD patients is well known. However, the existence of a significant literature demonstrating that addictive drugs impair cell growth ${ }^{29}$ on the one hand and stimulate cellular apoptosis ${ }^{30-34}$ on the other, suggests that it is theoretically conceivable that substance dependence might actually be accelerating the ageing process in accordance with the cellular hypothesis of ageing. ${ }^{35,36}$ Indeed, the ageing process itself has increasingly been characterised as a stem cell disorder. ${ }^{37-40}$

Our interest in this field was triggered when we noted that hair greying occurred more frequently in our SUD patients than in patients who did not present with addiction (N-SUD) and formal quantitation of this hypothesis demonstrated a highly significant difference between SUD patients and our medical patients who we used as a control sample of convenience. ${ }^{41}$ Hair greying of course is the sine qua non of human ageing, and has been shown to be due to a stem cell failure amongst the hair bulge melanocytic stem cells. ${ }^{42-44}$ Several recent papers from this clinic and elsewhere document the increased incidence of pathologies associated with ageing in SUD patients. In addition to greying of the hair, these pathologies include severe dental disease, ${ }^{45,46}$ atherosclerotic coronary disease, ${ }^{30,31}$ osteoporosis, ${ }^{47,48}$ neuropsychiatric disorders ${ }^{16,49}$ and lowered sperm count. ${ }^{50,51}$ Direct demonstration that this is related to lower circulating stem cell counts has also been reported in this group ${ }^{52}$ and the suggestion that this may in turn be associated with disorders of DNA repair may be implied by the finding of an elevated incidence of cervical malignancy amongst substance dependent females. ${ }^{53,54}$ The hypothesis that addiction might be accelerating the ageing process was further strengthened by our recent demonstration from clinical biochemical and immunological results that various immune and biochemical markers followed an altered and apparently progeroid time course in SUD patients compared to medical controls. ${ }^{55}$

Considerations such as these prompted us to examine whether a possible link might exist, at least at the statistical level, between the dental and mental disorders previously described in our clinic population, ${ }^{45,53}$ for much the same reasons as Kirkpatrick and colleagues sought confirmation of the view that schizophrenia might represent a systemic disorder ${ }^{14,15}$ in that both the limbic system and the dentition $^{56}$ require appropriate stem cell function to maintain optimum health and function. Moreover, there have been several recent reports of an oral-systemic disease link, for which aggressive periodontitis is a marker. ${ }^{1,6,57,58}$ Our interest was therefore considerably stirred when we noted a statistical association between the dental and mental pathologies of patients. While this association is observational only and mechanistic studies have for the most part not as yet been completed, the intriguing consistency of this finding with a progeroid model of the pathophysiology of addiction together with the various ramifications of such a conceptual paradigm motivated the present report in the hope of stimulating the investigative interest of other groups.

\section{METHODS}

\section{Patient selection and surveys}

Consecutive patients were selected presenting to our family medicine clinic in 2005. They were asked a number of questions relating to variables of interest and their mouth was examined medically, as has been described. Substance dependent patients presented specifically for management of their addiction, while medical patients presented for some other medical problem. Details were recorded on a hard copy spreadsheet and the data entered into an Excel spreadsheet.

\section{Drug use}

Drug use was determined by personal recall. Patients were asked specifically for their lifetime use of tobacco, alcohol, cannabis, heroin, morphine, methadone and amphetamines, with relation to the usual dose consumed and the total duration (termination date to initiation date) for which it was used.

\section{Mental status}

The psychiatric status of the patients was determined as has been previously reported. Patients were asked to give their psychiatric history from personal recall. The diagnoses of particular interest and to which patients were asked to respond were depression, anxiety, bipolar disorder, psychotic illness, schizophrenia, mental retardation, ADHD, aggression and epilepsy. The number of diagnoses they provided was simply summed to form a number of psychiatric diagnoses. The severity of those psychiatric diagnoses were scored by the clinician 1, 2 or 3 as follows: 1 relates to inactive or controlled disorders, 2 relates to average intensity, and 3 relates to a disorder of severe nature such that the life course was altered by it, and major treatment and/or hostel accommodation and/or multiple hospitalisations were required. The mental index (MI) was calculated as the product of the number of disorders multiplied by the severity score.

\section{Dental status}

The techniques for determining dental status have been previously reported. ${ }^{45}$ Teeth were examined by a medically trained practitioner only as dental services were not readily available to these patients. Teeth were scored as 'absent' if they were not clinically detected in the mouth. Teeth were scored as 'rotten' if the supra-gingival portion was more than $50 \%$ eroded by apparently carious processes. The number of absent and rotten teeth was summed $(A+R)$. A Dental Severity Score (DSS) was assigned to the overall dentition according to the following protocol: (1) fine-normal; (2) mild, if only mild abnormalities were present; (3) mild to moderate, if the abnormalities were between mild and moderate; (4) moderate, if two or more teeth were 50-100\% absent; (5) moderate to severe, if the abnormalities were between moderate and severe; (6) severe, if six or more teeth were either absent or 50\% absent; (7) very severe, if most teeth were absent and/or there was severe periodontitis in the associated gum tissue. The severity factor associated with these various grades were as follows: 1.0, 1.5, 2.0, 2.5, 3.0, 3.5, 4.0. The dental index (DI) was defined as the product of the number of rotten and absent teeth multiplied by the dental severity score $(\mathrm{DI}=(\mathrm{A}+\mathrm{R}) \times \mathrm{DSS})$. 


\section{Data analysis and statistics}

Data is listed as mean \pm S.D. Statistical tests were performed for Student's T in Microsoft Excel, for dichotomous categorical variables by Chi squared tables in EpiInfo from the Centres for Disease Control in Atlanta, Georgia, and multivariate regression and graphs were prepared using 'Statistica' software from Statsoft, Tulsa, Oklahoma on a Dell personal computer. Multivariate regression was performed using the standard technique in the General Regression Module of Statistica. Missing data was deleted. For the purposes of examining the interaction between age and addiction status only, the age variable was categorised into three groups. $\mathrm{P}<0.05$ was considered significant.

\section{Ethical approval}

Patients were studied as one component of their clinical care during routine scheduled appointments at the clinic. All work was undertaken with explicit informed patient consent. All studies were carried out in accordance with the Declaration of Helsinki, and were approved by the Human Ethics Research Committee (HREC) of the Southcity Family Medical Centre, which is a National Health and Medical Research Council of Australia registered HREC.

\section{Funding}

No external source of funding was available.

\section{RESULTS}

Sample size characteristics are listed in Table 1. While there were 249 patients in the SUD group and 134 in the N-SUD group, the groups had a substantial age disparity. The mean ages ( \pm S.D.) were $32.69 \pm 8.12$ and $46.25 \pm 20.67$ years in SUD and N-SUD groups, respectively. Limiting consideration to only those patients less than 57 years of age eliminated this disparity, and the two groups then had mean ages of $32.59 \pm 7.98$ and $35.69 \pm 8.12$ years, respectively $(p=0.074)$. This had the effect of removing from consideration $0.40 \%$ and $32.09 \%$ of the two samples, respectively. The group less then 57 years formed the main focus of the analysis. The gender ratios were $70.97 \%$ vs $59.34 \%$ male respectively $(\mathrm{p}=0.042)$.

\section{Table1 Sociodemographic characteristics of study patients}

\begin{tabular}{|l|l|l|}
\hline Parameter & SUD & N-SUD \\
\hline WHOLE SAMPLE & & \\
\hline Age range & $18-56$ & $1-95$ \\
\hline Sample size & 249 & 134 \\
\hline$\%$ male & $71.08 \%$ & $61.19 \% 0^{*}$ \\
\hline Mean age (SD) & $32.69(8.12)$ & $46.25(20.67)^{* * *}$ \\
\hline$<57$ YEARS & & $1-56$ \\
\hline Age range & $18-56$ & 91 \\
\hline Sample size & 248 & $59.79 \% *$ \\
\hline$\%$ male & $70.97 \%$ & $35.65(15.45)$ \\
\hline Mean age (SD) & $32.59(7.98)$ & $32.09 \%$ \\
\hline \begin{tabular}{l} 
\% sample excluded \\
\hline$* 0.05$ \\
$* * * 001$
\end{tabular} & $0.40 \%$ & \\
\hline
\end{tabular}

A

Dental Index by Age by Addiction Status D I N-SUD $=-11.9207+0.6427^{*} x$

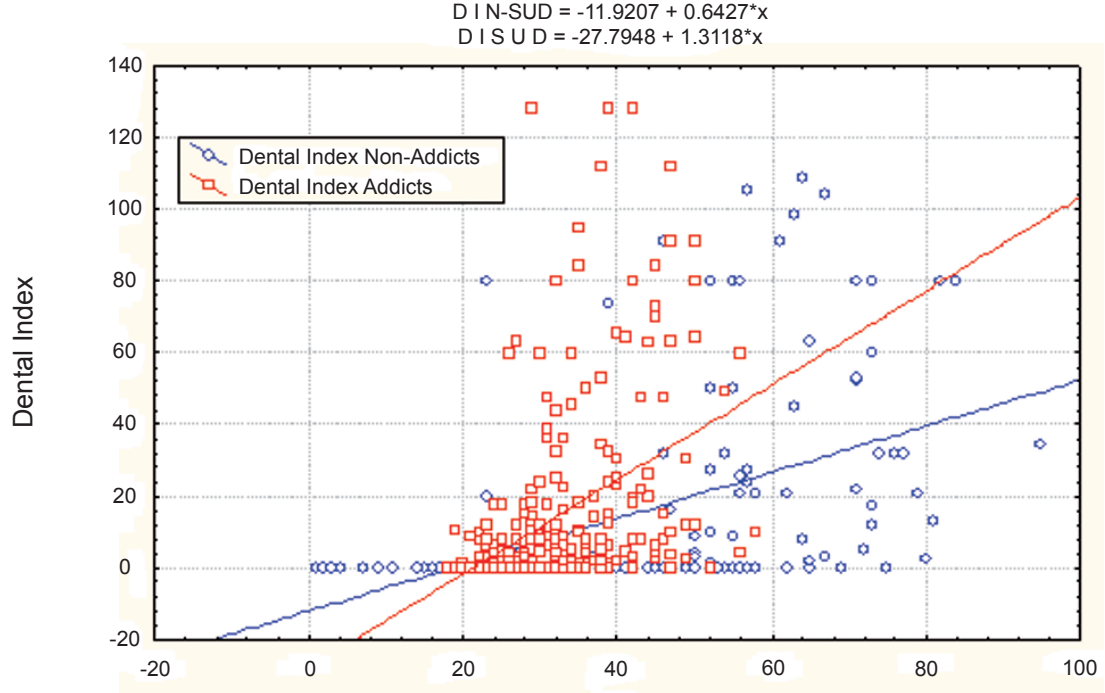

B

Mental Index by Age by Addiction Status M I N-SUD $=0.7318+0.0102^{*} \times$ $M I S \cup D=2.8084+0.0057^{*} x$

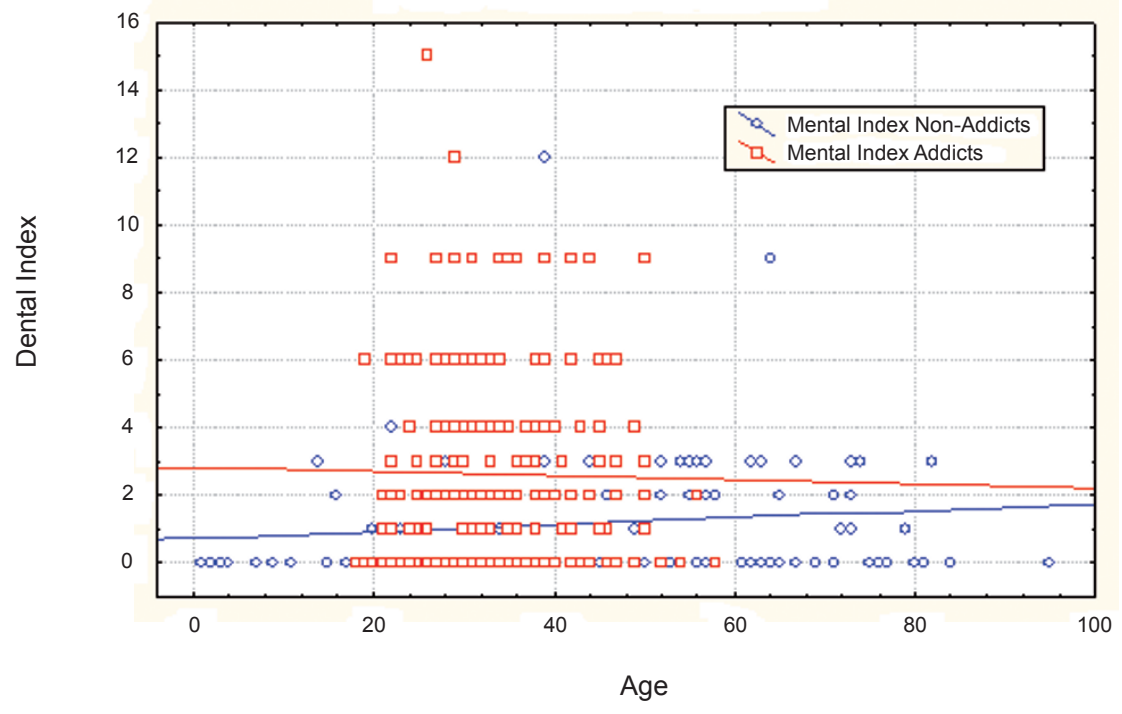

Fig. 1 Dental index and mental index by age by addiction status 
The drug use in the group less than 57 years of age is recorded in Table 2 for average amounts of drugs used by class, for the duration in years for which they were used, and for the various dose-duration products for the various common drugs of abuse in Australia. Inspection of this table reveals that the SUD group used more addictive substances both of the legal and the illicit class than the N-SUD group, and that the change occurred with a high degree of significance across all drugs and all classes. For the dose-duration products, the between group difference was particularly highly significant.

Figure 1 shows the time course of the dental index and mental index with age, along with their respective lines of best fit. There appears to be a clear separation of the two groups with age. As has been previously reported, there is a clear separation between the SUD and N-SUD groups for both of these indices. The mean ( \pm S.D.) dental index was $15.11 \pm$ 25.99 and $9.36 \pm 21.57$ in the SUD and NSUD groups respectively ( $p=0.041)$, and the mean mental index was $2.63 \pm 2.76$ vs $1.21 \pm 1.77$ ( $\mathrm{p}<0.0001)$ respectively.

The interaction factor for the mental index calculated between age and addiction status approached significance at $p$ $=0.082$ in the whole group and $p=0.091$ in the group less than 57 years. With respect to the dental index the interaction factor for age and addiction status was significant at $p=0.046$ in patients younger than 57 years, and $p=0.149$ in the whole group.

Figure 2 shows the relationships between the dental and mental indices. The bivariate correlations between dental index and mental index were significant in both the SUD and the N-SUD groups as shown in Table 3, both for all ages and in the age adjusted group less than 57 years of age. As shown in Table 3, the relevant correlations were significant at the $p=0.001,0.030$ and 0.003 levels in the N-SUD group, the SUD group and the whole patient group at all ages, and at the $p=0.02,0.030$ and 0.001 levels for patients less than 57 years of age. Other statistics of the bivariate correlations are listed in Table 3.

The bivariate and multivariate associations of the dental and mental index

\section{Table 2 Drug use in study patients}

\begin{tabular}{|c|c|c|}
\hline Parameter & Addicts & Medical \\
\hline \multicolumn{3}{|l|}{ Dose \&t duration } \\
\hline Cigarette numbers & $16.47(11.03)$ & $4.24(9.12)^{* * * *}$ \\
\hline Cigarette duration (yrs) & $14.52(9.42)$ & $4.87(10.75)^{* * * *}$ \\
\hline Alcohol size (g/d) & $8.36(20.95)$ & $1.26(7.54)^{* * * *}$ \\
\hline Alcohol duration (yrs) & $3.10(6.42)$ & $1.48(5.72)^{*}$ \\
\hline Cannabis size ( $g / d)$ & $2.61(5.09)$ & $0.21(1.14)^{* * * *}$ \\
\hline Cannabis duration (yrs) & $7.38(7.96)$ & $0.99(4.38)^{* * * *}$ \\
\hline Heroin size $(\mathrm{g} / \mathrm{d})$ & $0.56(0.98)$ & $0.00^{* * * *}$ \\
\hline Heroin duration (yrs) & $9.73(7.90)$ & $0.00^{* * * *}$ \\
\hline Morphine size (g/d) & $0.05(0.19)$ & $0.00^{* * *}$ \\
\hline Morphine duration (yrs) & $1.08(3.96)$ & $0.00^{* * * *}$ \\
\hline Methadone max. dose & $30.59(49.68)$ & $0.00^{* * * *}$ \\
\hline Methadone duration (yrs) & $1.49(3.46)$ & $0.00^{* * * *}$ \\
\hline Amphetamine size $(\mathrm{g} / \mathrm{d})$ & $0.51(1.46)$ & $0.01(0.10)^{* * * *}$ \\
\hline Amphetamine duration (yrs) & $1.77(4.15)$ & $0.10(0.94)^{* * * *}$ \\
\hline \multicolumn{3}{|l|}{ Dose-duration products } \\
\hline Cigarette index (Cig-yrs) & $278.54(250.91)$ & $104.45(299.13)^{* * * *}$ \\
\hline Alcohol index (g-yrs) & $75.87(224.57)$ & $20.32(108.18)^{* *}$ \\
\hline THC index (g-yrs) & $28.37(61.43)$ & $2.28(11.08)^{* * * *}$ \\
\hline Heroin index (g-yrs) & $6.35(11.15)$ & $0.00^{* * * *}$ \\
\hline Morphine index (g-yrs) & $0.36(1.51)$ & $0.00^{* * *}$ \\
\hline Methadone index (mg-yrs) & $151.25(439.06)$ & $0.00^{* * * *}$ \\
\hline Amphetamine index (g-yrs) & $3.16(9.80)$ & $0.10(1.94)^{* * * *}$ \\
\hline $\begin{array}{l}\text { Data as mean }( \pm S . D .) \\
{ }^{* *} p<0.05 \\
*{ }^{* * *} p<0.01 \\
*^{* * * *} p<0.001 \\
{ }^{* * * *} p<0.0001\end{array}$ & & \\
\hline
\end{tabular}

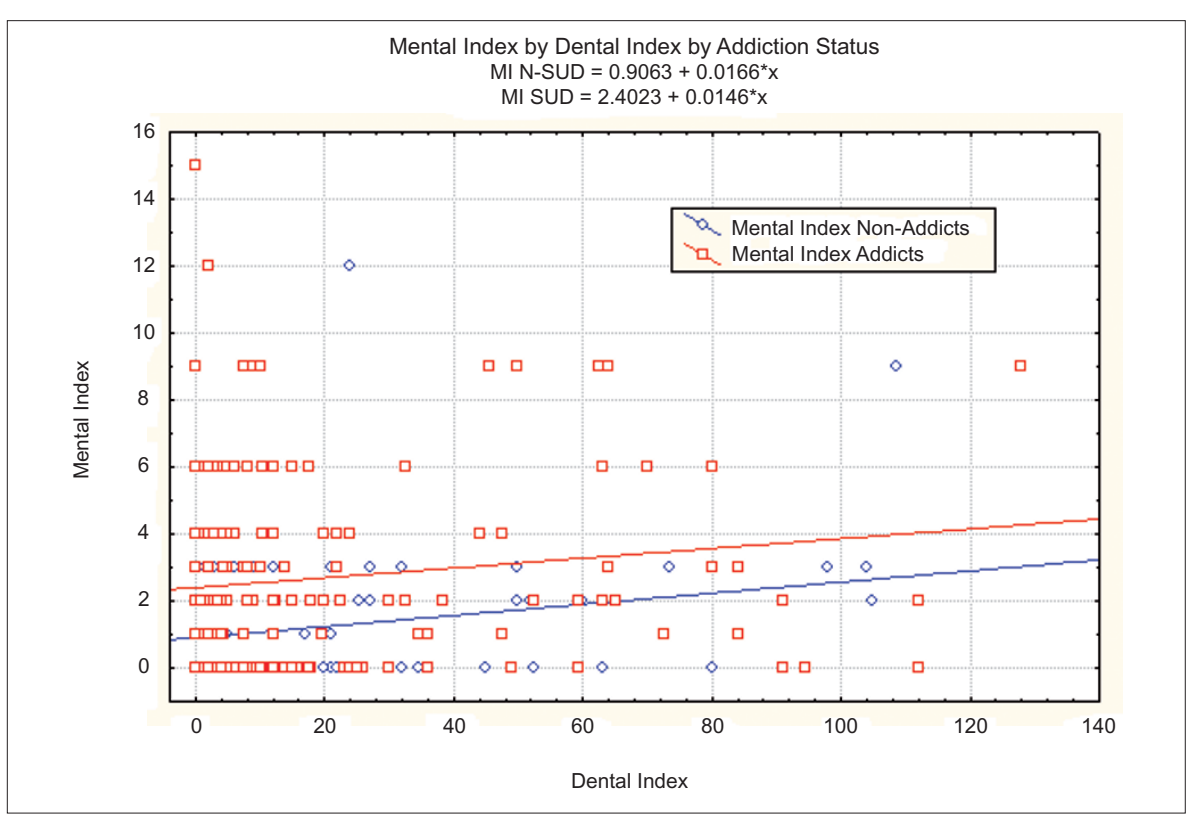

Fig. 2 Mental index by dental index 
have previously been reported..$^{26,45}$ It was of considerable interest to note, however, that at multivariate regression the reported bivariate associations between the dental and mental index continued to be significant, even after adjustment for other variables. This analysis was performed for patients of all ages, as age could be included as a variable in the model which was therefore age adjusted appropriately. Hence when the mental index was regressed against measures of dose-duration of the use of tobacco, alcohol, cannabis, amphetamine, heroin, morphine, methadone, gender, addiction status and age, the following variables (in order) proved statistically significant: cannabis use, amphetamine use, addiction status, alcohol use and the dental index (univariate $\mathrm{F}_{1,369}=5.50, \beta=0.1237$, $\mathrm{p}=0.0194$; whole model $\mathrm{R}^{2}=18.14 \%$, df $=(12,369), F=8.0364, p<0.00001)$. Similarly, when the same group of variables together with the selected psychiatric diagnoses anxiety and depression were regressed against the dental index, the following variables (in order) were shown to be significant: age, the mental index (univariate $\mathrm{F}_{1,363}=8.52, \beta=0.1757$, $p=0.0037$ ), the dose-duration product of tobacco and methadone use, and the dose-duration exposure to morphine (whole model $\mathrm{R}^{2}=21.70 \%, \mathrm{df}=(14,363)$, $\mathrm{F}=8.4647, \mathrm{p}<0.00001)$.

Figure 3 illustrates that the relationship between age, the dental index and the mental index as determined by the statistical surface of best fit (adjusted by negative exponential smoothing) appears to be quite different in the addict and non-addict groups. Whereas the general trend in the N-SUD patients is for age, the dental index and the mental index to be weakly positively associated, in the SUD group the most severe dental and mental index appear to be more associated with the younger ages, and for the average changes to be much worse. Some of these differences are reflected in scatterplots in Figures 1 and 2.

\section{DISCUSSION}

The main results of this study are that the dental and mental indices previously described are statistically associated in a highly significant manner. In a group of opiate-dependent patients and an age

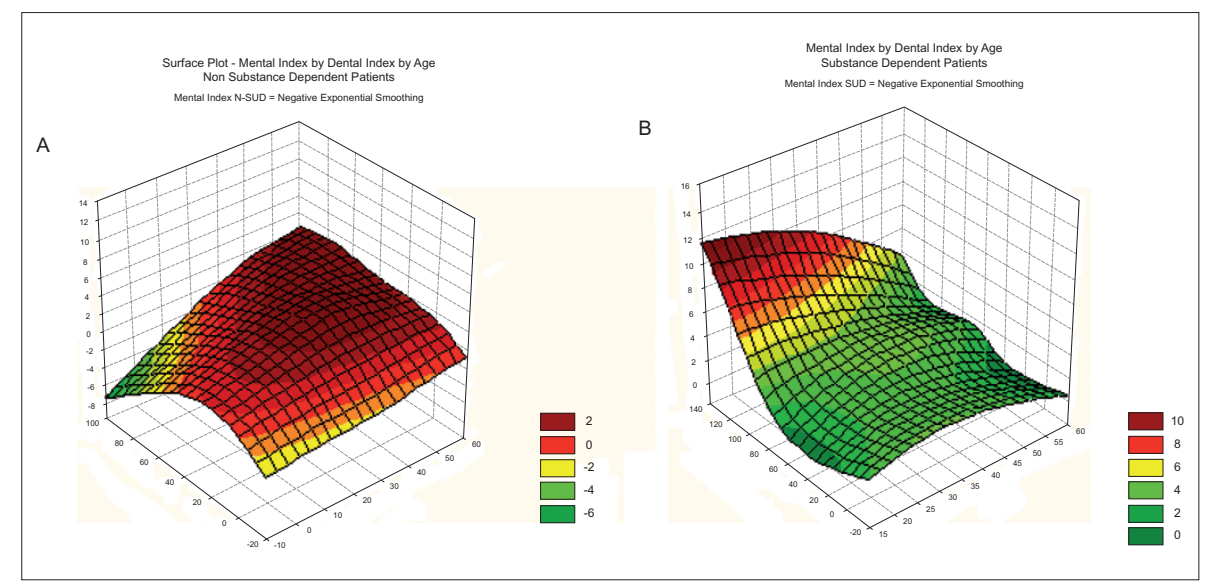

Figure 3 Mental index vs dental index vs age by addiction status

comparable group of medical controls, and in all patients combined, the correlational statistics for the dental and mental indices were highly significant on bivariate analysis. These relationships were sufficiently robust so that in multivariate analysis on controlling for various drug-related and clinical parameters, the significant association remained. It was also of note that in a three-way qualitative analysis between age and the dental and mental indices, the surfaces of best fit appeared to follow different patterns in the two patient groups.

Stem cell activity has been found to be critically involved in both pre- and post-natal tooth development ${ }^{59-62}$ and dental stabilisation in the periodontal ligament, ${ }^{63,64}$ involved in endothelial processes in tooth development, ${ }^{65}$ and very involved in the immunological surveillance and counteraction of the intense infective stimulus of the oral flora in the gingival sulcus. ${ }^{66}$ A serious hypothesis has developed that dental disorders may be associated with other systemic illnesses characterised by increased inflammation, such as carotid atherosclerosis, ${ }^{1,6}$ and this enjoyed currency particularly at the National Institute of Dental and Craniofacial Research (NIDCR), ${ }^{58,67,68}$ although contrary evidence has also been described..$^{57}$

Similarly, it is now well known that there is intense interest in the role of stem cells in the adult brain, particularly with reference to function in memory $^{69-71}$ and emotional stability, ${ }^{72-75}$ two areas which are particularly vulnerable in drug addiction. ${ }^{76-78} \mathrm{~A}$ focus on cellular health, growth renewal and replication as is suggested in general terms by this report explains several seeming paradoxes in addiction medicine, such as a finding that on a genome-wide screen for genes up-regulated in addiction, genes corresponding to synapse formation, intracellular signalling and transcription factors were found to be most significantly altered ${ }^{79}$ and have been specifically identified in studies of brain ageing. ${ }^{80}$ Cortical regions such as the prefrontal lobes, the right inferior

\begin{tabular}{l} 
Table 3 Bivariate correlations of dental and mental indices \\
\hline
\end{tabular}


frontal gyrus, the dorsolateral prefrontal cortex, the anterior cingulate and the deep white matter of the frontal lobes, well known to be impaired in addiction, ${ }^{54,55}$ have also been identified as sites particularly vulnerable to age-related declines. ${ }^{81}$ Medial temporal lobe including hippocampal volume loss has also been defined with age, and is an area well known to be involved with working memory and its disorders. Indeed a 60\% reduction in hippocampal neurogenesis is known to occur from adulthood to old age in the rat. ${ }^{82}$ Age-related changes in dopamine concentration, transporter availability and D2 and D3 receptor density $^{81}$ and glutamatergic synapse dysregulation, ${ }^{83}$ all of which have been identified as critical changes in addiction neuroscience, have been identified in the non-demented aged.

Similarly, an unexpected finding that hypertrophy of basal ganglia nuclei occurs in stimulant users ${ }^{84-87}$ might be explained by altered patterns of neuronogenesis and gliogenesis in response to brain injury or chemical insult ${ }^{88-92}$ and is consistent with the increased magnetic resonance spectroscopy signals for 'activated glial' cells and reduced neuronal metabolism which has been obtained from these structures. ${ }^{54,67}$ Neural stem cells normally differentiate into both glia and neurons, and in animals the latter migrate anteriorly in the rostral migratory stream to the olfactory bulb. Under the influence of toxins, and in a dopamine sensitive manner, the ratio of differentiation into the glial lineage increases and the glial progenitors move laterally into the basal ganglia which are thus seen to hypertrophy. A substantial $42 \mathrm{~cm}$ and $3.5 \mathrm{~kg}$ deficit of whole body growth over two years has been identified in a major NIH study of ADHD children treated with stimulant medication, ${ }^{30}$ which would clearly be consistent with the combined effects of a direct inhibition of cell growth together with appetite suppression. A recent paper from Sydney identified a rapid age-related progression of cardiac (including coronary atherosclerosis), pulmonary, hepatic, renal and multisystem disease in a group of decedent intravenous drug users, ${ }^{27}$ again implying that more generalised underlying mechanisms may be operating.
The very high rate of major and problematic psychopathology in addiction is increasingly well recognised r,78,93,94 $^{7 n d}$ it has recently been suggested that schizophrenia itself may reflect a syndrome of accelerated ageing, not just in the brain but throughout the organism..$^{14,15}$ Indeed, an association between treatment naïve non-affective psychoses and diabetes and the increased pulse pressure noted in older patients has been described. ${ }^{15} \mathrm{An}$ association between maternal prenatal stress and the risk of developing schizophrenia in later life has also been noted, ${ }^{15}$ and the role of stress in addiction is a major topic of ongoing investigation. ${ }^{95-98}$

In the context that ageing is increasingly being seen as a disorder of stem cell function and tissue repair, and that addiction is associated with an acceleration of age-related processes, ${ }^{27,41,52,55}$ the possible conceptual issues raised by the present observational enquiry are of particular interest. It is worth considering the extent to which the findings of this study are generalisable to other populations. While the present author is not aware of any particular differences in racially different groups in the terms discussed herein, more detailed description of such variations would require further studies. Similarly it is noteworthy that many of the deleterious changes described are likely to be exacerbated in conditions of socio-economic disadvantage, and most likely also in conditions of over-nutrition. Again further, more detailed work is required to address such issues.

The present study provides only limited insight into mechanistic pathways which might account for this fascinating association. While indices of the lifetime consumption of drugs were related to both dental and mental pathologies themselves, this clinic does not as yet possess the technical capacity to link these results with cellular, stem cell or molecular markers of cellular senescence, cell cycle activity, or DNA damage. Moreover, as we had no information on other measures of lifestyle adversity such as overdose histories, nutritional inadequacy, lifetime trauma, imprisonment or stress, it is conceivable that either lifestyle or pharmacological mechanisms might be responsible for many of the perturbations described. Our study had several other limitations. The observer was not blinded to the status of the patients. The somewhat subjective nature of the severity score assignment for the dental and mental indices leaves this work open to a charge of bias. Formal measurement by trained dental clinicians and psychologists respectively would be recommended in a formal funded study. The use of molecular and cellular laboratory measures of ageing and senescence would be preferable to avoid some of these limitations. Again, the use of several markers of cellular ageing and the use of several molecular measures of age-related change would be preferred. While such shortcomings are acknowledged, given the salience of the present findings and their consistency with a wider body of data relating to the basic sciences of addiction, it is not believed that these limitations are irrefutable. On the other hand, the study does have several strengths such as drug use information, data on disparate pathologies, timeliness, a novel conceptual framework, a substantial sample size and the relatively limited use made of statistical testing.

In summary, this study extends previous work documenting the well known increased rate of psychiatric co-morbidity and severe dental pathology occurring in substance use disorders by showing that simple summary indices of these two pathologies share a robust statistical association on both bivariate and multivariate analysis in our clinical population. While multivariate associations of both indices separately suggest that they are associated with various measures of lifetime drug use, a causal basis for this interesting association has not been elucidated. Clinical studies such as this and other recent work invite further mechanistic and molecular studies. The tantalising suggestion that one such link could be mediated through stem cell or progeroid processes particularly invites further investigation.

1. Desvarieux M, Demmer R T, Rundek T et al. Periodontal microbiota and carotid intima-media thickness: the Oral Infections and Vascular Disease Epidemiology Study (INVEST). Circulation 2005: 111: 576-582.

2. Grau A J, Becher H, Ziegler C M et al. Periodontal disease as a risk factor for ischemic stroke. Stroke 2004; 35: 496-501. 
3. Joshipura K J, Hung H C, Rimm E B, Willett W C, Ascherio A. Periodontal disease, tooth loss, and incidence of ischemic stroke. Stroke 2003: 34: 47-52.

4. Mattila K J. Dental infections as a risk factor for acute myocardial infarction. Eur Heart J 1993; 14(Suppl K): 51-53.

5. Mattila K J, Valle M S, Nieminen M S, Valtonen V $V$, Hietaniemi K L. Dental infections and coronary atherosclerosis. Atherosclerosis 1993:

103: 205-211.

6. Desvarieux M, Demmer R T, Rundek T et al. Relationship between periodontal disease, tooth loss, and carotid artery plaque: the Oral Infections and Vascular Disease Epidemiology Study (INVEST). Stroke 2003; 34: 2120-2125.

7. Espinola-Klein C, Rupprecht H J, Blankenberg S et al. Impact of infectious burden on progression of carotid atherosclerosis. Stroke 2002; 33: 2581-2586.

8. Espinola-Klein C, Rupprecht H J, Blankenberg S et al. Impact of infectious burden on extent and long-term prognosis of atherosclerosis. Circulation 2002; 105: 15-21.

9. Kiechl S, Egger G, Mayr M et al. Chronic infections and the risk of carotid atherosclerosis: prospective results from a large population study. Circulation 2001; 103: 1064-1070.

10. Papapanou P N, Neiderud A M, Papadimitriou A, Sandros J, Dahlen G. "Checkerboard" assessments of periodontal microbiota and serum antibody responses: a case-control study. J Periodontol 2000; 71: 885-897.

11. Slade G D, Ghezzi E M, Heiss G, Beck J D, Riche E Offenbacher $S$. Relationship between periodontal disease and C-reactive protein among adults in the Atherosclerosis Risk in Communities study. Arch Intern Med 2003; 163: 1172-1179.

12. Ebersole J L, Machen R L, Steffen M J, Willmann D E. Systemic acute-phase reactants, C-reactive protein and haptoglobin, in adult periodontitis. Clin Exp Immunol 1997; 107: 347-352.

13. Wu T, Trevisan M, Genco R J, Dorn J P, Falkner K L, Sempos C T. Periodontal disease and risk of cerebrovascular disease: the first national health and nutrition examination survey and its follow-up study. Arch Intern Med 2000; 160: 2749-2755.

14. Kirkpatrick B, Hack G D, Higginbottom E, Hoffacker $D$, Fernandez-Egea E. Palate and dentition in schizophrenia. Schizophr Res 2007; 91: 187-191.

15. Kirkpatrick B, Messias E, Harvey P D, FernandezEgea E, Bowie C R. Is schizophrenia a syndrome of accelerated aging? Schizophr Bull 2007 Dec 21 [Epub ahead of print].

16. United Nations Office of Drugs and Crime. World drug report 2007. Vienna: UN ODC, 2007.

17. UNAIDS. 2006 report on the global AIDS epidemic. Geneva: UNAIDS, 2007.

18. Gottschalk LA, McGuire F L, Heiser J F, Dinovo E C, Birch H. Drug abuse deaths in nine cities: a survey report. Rockville, MD, USA: National Institutes on Drug Abuse, 1979. NIDA Research Monograph 29.

19. Lombard D B, Chua K F, Mostoslavsky R, Franco S, Gostissa M, Alt F W. DNA repair, genome stability, and aging. Cell 2005; 120: 497-512.

20. Gronbladh L, Gunne L. Methadone-assisted rehabilitation of Swedish heroin addicts. Drug Alcohol Depend 1989; 24: 31-37.

21. Hser Y I, Hoffman V, Grella C E, Anglin M D. A 33-year follow-up of narcotics addicts. Arch Gen Psychiatry 2001; 58: 503-508.

22. Gronbladh L, Ohlund LS, Gunne L M. Mortality in heroin addiction: impact of methadone treatment. Acta Psychiatr Scand 1990; 82: 223-227.

23. Gunne L M, Gronbladh L. The Swedish methadone maintenance program: a controlled study. Drug Alcohol Depend 1981; 7: 249-256.

24. Poser W, Koc J, Ehrenreich H. Methadone maintenance treatment. Methadone treatment can reduce mortality. BMJ 1995; 310: 463.

25. Darke S. Degenhardt L, Mattick R. Mortality amongst illicit drug users: epidemiology, causes and intervention. Cambridge: Cambridge University Press, 2007

26. Reece A S. Chronology and patterns of psychiatric morbidity in substance dependent and medical patients. Australas Psychiatry 2008; In Press.

27. Darke S, Kaye S, Duflou J. Systemic disease among cases of fatal opioid toxicity. Addiction 2006; 101: 1299-1305.

28. Hulse G K, English D R, Milne E, Holman C D. The quantification of mortality resulting from the regular use of illicit opiates. Addiction 1999; 94: 221-229.

29. Zagon I S, Verderame M F, McLaughlin P J. The biology of the opioid growth factor receptor (OGFr). Brain Res Brain Res Rev 2002; 38: 351-376.

30. Mao J, Sung B, Ji R R, Lim G. Neuronal apoptosis associated with morphine tolerance: evidence for an opioid-induced neurotoxic mechanism. J Neurosci 2002; 22: 7650-7661.

31. Maccarrone M, Lorenzon T, Bari M, Melino G, Finazzi-Agro A. Anandamide induces apoptosis in human cells via vanilloid receptors. Evidence for a protective role of cannabinoid receptors. J Biol Chem 2000; 275: 31938-31945

32. Bari M, Battista N, Fezza F, Finazzi-Agro A, Maccarrone M. Lipid rafts control signaling of type-1 cannabinoid receptors in neuronal cells. Implications for anandamide-induced apoptosis. J Biol Chem 2005; 280: 12212-12220.

33. Krasnova I N, Ladenheim B, Cadet J L. Amphetamine induces apoptosis of medium spiny striatal projection neurons via the mitochondria-dependent pathway. FASEB J 2005; 19: 851-853.

34. Li G, Xiao Y, Zhang L. Cocaine induces apoptosis in fetal rat myocardial cells through the p38 mitogen-activated protein kinase and mitochondrial/cytochrome c pathways. J Pharmacol Exp Ther 2005; 312: 112-119.

35. Hadley E C, Lakatta E G, Morrison-Bogorad M, Warner H R, Hodes R J. The future of aging therapies. Cell 2005; 120: 557-567.

36. Kirkwood T B. Understanding the odd science of aging. Cell 2005; 120: 437-447.

37. Rossi D J, Bryder D, Zahn J M et al. Cell intrinsic alterations underlie hematopoietic stem cell aging. Proc Natl Acad Sci U SA 2005; 102: 9194-9199.

38. Schlessinger D, Van Zant G. Does functional depletion of stem cells drive aging? Mech Ageing Dev 2001: 122: 1537-1553.

39. Bryder D, Rossi D J, Weissman I L. Hematopoietic stem cells: the paradigmatic tissue-specific stem cell. Am J Patho/ 2006; 169: 338-346.

40. Rando T A. Stem cells, ageing and the quest for immortality. Nature 2006; 441: 1080-1086.

41. Reece A S. Hair graying in substance addiction. Arch Dermatol 2007; 143: 116-118.

42. Nishimura E K, Jordan S A, Oshima H et al. Dominant role of the niche in melanocyte stem-cell fate determination. Nature 2002; 416: 854-860.

43. Steingrimsson $E_{1}$ Copeland N G, Jenkins N A Melanocytes and the microphthalmia transcription factor network. Annu Rev Genet 2004; 38: 365-411.

44. Steingrimsson $E_{1}$ Copeland N G, Jenkins N A. Melanocyte stem cell maintenance and hair graying. Cell 2005; 121: 9-12

45. Reece A S. Dentition of addiction in Queensland: poor dental status and major contributing drugs. Aust Dent J 2007; 52: 144-149.

46. Osborn M. Butler T, Barnard P D. Oral health status of prison inmates - New South Wales, Australia. Aust Dent J 2003; 48: 34-38.

47. Kim T W, Alford D P, Malabanan A, Holick M F, Samet J H. Low bone density in patients receiving methadone maintenance treatment. Drug Alcohol Depend 2006; 85: 258-262.

48. Idris A I, van't Hof R J, Greig I R et al. Regulation of bone mass, bone loss and osteoclast activity by cannabinoid receptors. Nat Med 2005; 11: 774-779.

49. Australian Institute of Health and Welfare. National comorbidity initiative: a review of data collections relating to people with coexisting substance use and mental health disorders. Canberra: AlHW, 2005.

50. Huang H F S, Nahas G G, Hembree W C III. Effects of marihuana inhalation on spermatogenesis of the rat. In Nahas G G, Sutin K M, Harvey D J, Agurell S (eds) Marihuana and medicine. pp 359-
366. Totowa, New Jersey: Humana Press, 1999.

51. Hembree W C III, Nahas G G, Zeidenberg P, Huang $\mathrm{H}$ FS. Changes in human spermatozoa associated with high dose marihuana smoking. In Nahas G G, Sutin K M, Harvey D J, Agurell S (eds) Marihuana and medicine. pp 367-378. Totowa, New Jersey: Humana Press, 1999

52. Reece AS, Davidson P. Deficit of circulating stemprogenitor cells in opiate addiction: a pilot study. Subst Abuse Treat Prev Policy 2007; 2: 19.

53. Reece A. Lifetime prevalence of cervical neoplasia in addicted and medical patients. Aust N Z J Obstet Gynaecol 2007; 47: 419-423.

54. Sidney $S$, Quesenberry C P Jr, Friedman G D, Tekawa I S. Marijuana use and cancer incidence (California, United States). Cancer Causes Control 1997; 8: 722-728.

55. Reece A S. Evidence of accelerated ageing in clinical drug addiction from immune, hepatic and metabolic biomarkers. Immun Ageing 2007: 4: 6.

56. Huang G T. A paradigm shift in endodontic management of immature teeth: conservation of stem cells for regeneration. J Dent 2008; 36: 379-386.

57. Tonetti M S, D'Aiuto F, Nibali L et al. Treatment of periodontitis and endothelial function. N Engl J Med 2007; 356: 911-920.

58. National Institute of Dental and Craniofacial Research. Webpage: Looking at the periodontal-systemic disease connection. Inside Scoop, July 2005. http://www.nidcr.nih.gov/Research/ ResearchResults/InterviewsOHR/TIS072005.htm (accessed 9 October 2008).

59. Andl T, Ahn K, Kairo A et al. Epithelial Bmpr1a regulates differentiation and proliferation in postnatal hair follicles and is essential for tooth development. Development 2004; 131: 2257-2268.

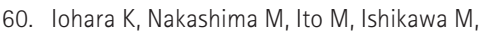
Nakasima A, Akamine A. Dentin regeneration by dental pulp stem cell therapy with recombinant human bone morphogenetic protein 2. J Dent Res 2004; 83: 590-595.

61. Nakashima M, lohara K, Ishikawa M et al. Stimulation of reparative dentin formation by ex vivo gene therapy using dental pulp stem cells electrotransfected with growth/differentiation factor 11 (Gdf11). Hum Gene Ther 2004; 15: 1045-1053.

62. Ohazama A, Modino S A, Miletich I, Sharpe P T. Stem-cell-based tissue engineering of murine teeth. J Dent Res 2004; 83: 518-522.

63. Kung C. A possible unifying principle for mechanosensation. Nature 2005; 436: 647-654.

64. Seo B M, Miura M, Gronthos S et al. Investigation of multipotent postnatal stem cells from human periodontal ligament. Lancet 2004; 364: 149-155

65. Wojciak-Stothard B, Torondel B, Tsang L Y et al. The ADMA/DDAH pathway is a critical regulator of endothelial cell motility. J Cell Sci 2007; 120: 929-942.

66. Kidd E A M. Joyston-Bechal S. Essentials of dental caries. The disease and its management. 2nd ed. Oxford: Oxford University Press, 2002.

67. National Institute of Dental and Craniofacial Research. Periodontal (gum) disease. Bethesda, MD: NIDCR, 2004.

68. National Institute of Dental and Craniofacial Research website. Oral complications of systemic diseases webpage. http://www.nidcr.nih.gov/OralHealth/OralHealthInformation/SystemicDiseases/ (accessed 9 October 2008).

69. Drapeau E, Mayo W, Aurousseau C, Le Moal M, Piazza PV, Abrous D N. Spatial memory performances of aged rats in the water maze predict levels of hippocampal neurogenesis. Proc Natl Acad Sci U SA 2003; 100: 14385-14390.

70. Fonseca R, Nagerl U V, Morris R G, Bonhoeffer T. Competing for memory: hippocampal LTP under regimes of reduced protein synthesis. Neuron 2004; 44: 1011-1020.

71. Kee N, Teixeira C M, Wang A H, Frankland P W. Preferential incorporation of adult-generated granule cells into spatial memory networks in the dentate gyrus. Nat Neurosci 2007; 10: 355-362.

72. Sahay A, Hen R. Adult hippocampal neurogenesis in depression. Nat Neurosci 2007; 10: 1110-1115. 
73. Perera T D, Coplan J D, Lisanby S H et al. Antidepressant-induced neurogenesis in the hippocampus of adult nonhuman primates. J Neurosci 2007; 27: 4894-4901.

74. Martinowich K, Manji H, Lu B. New insights into BDNF function in depression and anxiety. Nat Neurosci 2007; 10: 1089-1093.

75. Gould T D, Dow E R, O'Donnell K C, Chen G, Manji $\mathrm{H}$ K. Targeting signal transduction pathways in the treatment of mood disorders: recent insights into the relevance of the Wnt pathway. CNS Neurol Disord Drug Targets 2007; 6: 193-204.

76. Bao G, Kang L, Li H et al. Morphine and heroin differentially modulate in vivo hippocampal LTP in opiate-dependent rat. Neuropsychopharmacology 2007; 32: 1738-1749.

77. Moore TH, Zammit S, Lingford-Hughes A et al. Cannabis use and risk of psychotic or affective mental health outcomes: a systematic review. Lancet 2007: 370: 319-328.

78. Nordentoft $M$, Hjorthoj C. Cannabis use and risk of psychosis in later life. Lancet 2007; 370: 293-294.

79. Li T K, Volkow N D, Baler R D, Egli M. The biological bases of nicotine and alcohol co-addiction. Biol Psychiatry 2007; 61: 1-3.

80. Nicolle M M, ZH-Y, Bizon J.L. In Riddle D R (ed) Brain aging: models, methods and mechanisms. pp 213-228. Boca Raton, FL: CRC Press, Taylor and Francis Group, 2007.

81. Hedden T. Imaging cognition in the aging human brain. In Riddle D R (ed) Brain aging: models, methods, and mechanisms. pp 251-278. Boca Raton, FL: CRC Press, Taylor and Francis Group, 2007.

82. Riddle D R, Lichtenwalner R J. Neurogenesis in the adult and aging brain. In Riddle D R (ed) Brain aging: models, methods, and mechanisms. pp 127-158. Boca Raton, FL: CRC Press, Taylor and
Francis Group, 2007.

83. Shi L, Adams M, Brunso-Bechtold J K. Subtle alterations in glutamatergic synapses underlie the aging related decline in hippocampal function. In Riddle D R (ed) Brain aging: models, methods, and mechanisms. pp 189-212. Boca Raton, FL: CRC Press, Taylor and Francis Group, 2007.

84. Chang L, Cloak C, Patterson K, Grob C, Miller E N, Ernst T. Enlarged striatum in abstinent methamphetamine abusers: a possible compensatory response. Biol Psychiatry 2005; 57: 967-974.

85. Fowler J S, Volkow N D, Kassed C A, Chang L. Imaging the addicted human brain. Sci Pract Perspect 2007; 3: 4-16.

86. Jacobsen L K. Giedd J N, Gottschalk C, Kosten T $R$, Krystal J H. Quantitiative morphology of the caudate and putamen in patients with cocaine dependence. Am J Psychiatry 2001; 158: 486-489.

87. Jernigan $T$ L, Gamst A C, Archibald S L et al. Effects of methamphetamine dependence and HIV infection on cerebral morphology. Am J Psychiatry 2005; 162: 1461-1472.

88. Zhang R L, LeTourneau Y Gregg S R et al. Neuroblast division during migration toward the ischemic striatum: a study of dynamic migratory and proliferative characteristics of neuroblasts from the subventricular zone. J Neurosci 2007; 27: 3157-3162.

89. Yamashita T, Ninomiya M, Hernandez Acosta P et al. Subventricular zone-derived neuroblasts migrate and differentiate into mature neurons in the post-stroke adult striatum. J Neurosci 2006; 26: 6627-6636.

90. Nygren J, Wieloch T, Pesic J, Brundin P, Deierborg $T$. Enriched environment attenuates cell genesis in subventricular zone after focal ischemia in mice and decreases migration of newborn cells to the striatum. Stroke 2006; 37: 2824-2829.
91. Lin J H, Takano T, Arcuino G et al. Purinergic signaling regulates neural progenitor cell expansion and neurogenesis. Dev Biol 2007; 302: 356-366.

92. Corson P W, Nopoulos P, Miller D D, Arndt S, Andreasen N C. Change in basal ganglia volume over 2 years in patients with schizophrenia: typical versus atypical neuroleptics. Am J Psychiatry 1999; 156: 1200-1204.

93. Dyer K R, White J M. Patterns of symptom complaints in methadone maintenance patients. Addiction 1997; 92: 1445-1455.

94. Schreiber S, Peles E, Adelson M. Association between improvement in depression, reduced benzodiazepine (BDZ) abuse, and increased psychotropic medication use in methadone maintenance treatment (MMT) patients. Drug Alcohol Depend 2008; 92: 79-85.

95. Berton $\mathrm{O}$, Covington $\mathrm{H}$ E 3rd, Ebner $\mathrm{K}$ et al. Induction of deltaFosB in the periaqueductal gray by stress promotes active coping responses. Neuron 2007; 55: 289-300.

96. Fitzgerald L W, Ortiz J, Hamedani A G, Nestler E J. Drugs of abuse and stress increase the expression of GluR1 and NMDAR1 glutamate receptor subunits in the rat ventral tegmental area: common adaptations among cross-sensitizing agents. J Neurosci 1996: 16: 274-282.

97. Green T A, Alibhai I N, Hommel J D et al. Induction of inducible cAMP early repressor expression in nucleus accumbens by stress or amphetamine increases behavioral responses to emotional stimuli. J Neurosci 2006; 26: 8235-8242.

98. Marsteller D A, Gerasimov M R, Schiffer W K et al. Acute handling stress modulates methylphenidate-induced catecholamine overflow in the medial prefrontal cortex. Neuropsychopharmacology $2002 ; 27: 163-170$ 